\title{
Estudio bacteriológico de la calidad del pescado fresco, Bagre (Pseudoplatystoma sp.) y Mojarra Roja (Oreochromis sp.) comercializado en el municipio de El Colegio, Cundinamarca (Colombia)
}

\section{Lucía Constanza Corrales Ramírez MSc' , María Angélica Alvarado Ospina², Lady Alexandra Castillo Fonseca², Yury Constanza Camacho Beltran².}

\author{
1. Docente Investigador Universidad Colegio Mayor de Cundinamarca. \\ 2. Estudiantes del Programa de Bacteriología y Laboratorio Clínico de la Universidad Colegio Mayor de \\ Cundinamarca.
}

Correspondencia: Icorralesr07@gmail.com

Recibido: 03-10-2011 / Aceptado: 19-12-2011

\begin{abstract}
Resumen
En el Municipio El Colegio, Cundinamarca, se observa la necesidad de realizar controles periódicos sobre buenas prácticas de manufactura que disminuyan el grado de contaminación que pueda estar presentándose en los expendios de pescado fresco. El análisis bacteriológico permitió confirmar ausencia de los patógenos Salmonella s.p, Staphylococcus aureus, Escherichia coli y Vibrio cholerae, en contraste con la presencia en un alto índice de otro tipo de enterobacterias relacionadas en su mayoría con el agua de donde proviene el pescado, como C. amalonaticus y C. freundii en un 30\% de las muestras; K. oxytoca, E. cloacae, y E. tarda en un 10\% respectivamente. Para Mojarra Roja se aisló K. oxytoca, K. ozaenae, E. tarda, P. mirabilis en un $20 \%$ respectivamente y V. metschnikovii en un 10\%; microorganismos que en elevadas cantidades pueden representar un alto riesgo para la salud pública.
\end{abstract}

Palabras claves: pescado fresco, contaminación cruzada, buenas prácticas de manufactura (BPMs), cadena de comercialización.

Abstract
Bacteriological quality of fresh fish, Catfish (Pseudoplatystoma sp.) and Red Tilapia

(Oreochromis sp.), as marketed in the municipality of

El Colegio, Cundinamarca (Colombia)

In the municipality of El Colegio, Cundinamarca (Colombia) the need for regular checkson good manufacturing practices that reduce the degree of contamination that may be occurring in the fresh fish outlets was observed. Bacteriological analysis allowed to confirm the absence of Salmonella sp, Staphylococcus aureus, Escherichia coli, and Vibrio cholerae pathogens, contrasting to the presence in a high rate of other enterobacteria, related mostly with the water from which fish comes, such as C. amalonaticus and C. freundii in $30 \%$ of the samples, K. oxytoca, E. cloacae, and E. tarda on a I0\% respectively. In Red Tilapia, K. oxytoca, K. ozaenae, E. tarda, P. mirabilis were isolated with a $20 \%$ respectively, and V. metschnikoviiin 10\%. In large quantities, these microorganisms can pose a risk to public health.

Key words: fresh fish, cross-contamination, good manufacturing practices (GMPs), marketing chain. 


\section{Introducción}

El pescado es un alimento que experimenta una serie de cambios desde el momento de su captura debido a su composición, característica que lo convierte en un producto con un alto grado de susceptibilidad al deterioro y putrefacción- Los responsables de estos fenómenos son las enzimas que lo constituyen y los microorganismos que invaden los órganos y tejidos tan pronto sucede la muerte (1).

De los microorganismos son las bacterias las que más influyen en la vida útil del pescado. Sin embargo, no todas las que están presentes en el momento de la captura o recogida son capaces de multiplicarse durante el almacenamiento, solo una parte de estas acabará proliferando en gran cantidad y convirtiéndose en las responsables de la alteración. La época del año, las características de la alimentación, el área geográfica, la especie de pescado y el sistema de captura son determinantes del número y tipo de bacterias presentes inicialmente, mientras que las condiciones de manipulación y almacenamiento condicionan la flora alterante. Evidentemente, todas las manipulaciones de que sea objeto el pescado tras la captura o recogida van a afectar de forma notable la calidad microbiológica del mismo (2).

Los microorganismos bacterianos patógenos para el hombre y que se trasmiten por este producto se pueden dividir en dos grupos: especies cuyo hábitat natural es el agua (Vibrio cholerae, Aeromonas sp., etc.) y otros que están presentes en el agua por contaminación de origen fecal y se asocian al proceso de manipulación que posteriormente sufre el pescado (Escherichia coli, Salmonella sp. Listeria monocytogenes, Staphylococcus aureus) (2).

Los cambios que se producen desde la captura hasta la venta alteran las condiciones físicas, químicas y microbiológicas convirtiendo este producto en un alimento de alto riesgo para la salud del consumidor, sobre todo a través de la cadena de comercialización, en la cual se presentan una serie de puntos críticos que si no son controlados adecuadamente acaban por incidir sobre la calidad sanitaria del producto. Con la Ley 9 de 1979, el Decreto 3075 de 1997 y el Código de Prácticas para el pescado y los productos pesqueros (CAC/RCP 52-2003), se establecen una serie de parámetros obligatorios que deben cumplir los establecimientos para la actividad comercial que realizan, como son: un local con buenas condiciones de higiene, adecuado con áreas para el aseo personal, para la manipulación y almacenamiento, además de la indumentaria necesaria para cada uno de los empleados que manipulan el producto.

En Colombia, hasta el año 2003, se reportaron 5228 casos de enfermedades trasmitidas por alimentos (ETAs) de los cuales, la mayor proporción, se presentó en la región centro oriente (35\%). En esta región se encuentra el distrito y los departamentos con los mayores números de casos reportados: Bogotá 16.1\% (844) y Santander 7.9\% (415), aunque no todos los reportes se refieren a intoxicación con pescado fresco contaminado, al validar los resultados se demostró la presencia en gran cantidad de Salmonella $s p$. en establecimientos formales e informales de comercialización (2).

De acuerdo con lo anterior, este estudio determinó la calidad del pescado fresco, Bagre (Pseudoplatystoma $s p$.) y Mojarra Roja (Oreochromis sp.) que se expende en el municipio El Colegio, Cundinamarca, de acuerdo con los requisitos bacteriológicos establecidos en la Resolución 776 de 1998 (3). En dicha resolución, se establecen unos rangos mínimos en relación con la presencia de coliformes totales y patógenos como la Salmonella sp., Escherichia coli, Vibrio cholerae y Staphylococcus aureus. Además de relacionar el grado de contaminación que pueda presentarse con las prácticas de manipulación que utilizan los expendedores, teniendo en cuenta los factores de temperatura, almacenamiento y transporte que sufre el alimento antes de ser comercializado y de esta forma aportar a la comunidad conocimiento acerca de las buenas prácticas de manipulación y el manejo adecuado de este tipo de productos.

\section{Materiales y métodos}

El estudio inició con la identificación de los establecimientos encargados de la distribución de pescado fresco en el municipio de El Colegio, Cundinamarca, para así seleccionar la población de estudio. Una vez seleccionada se procedió a realizar una encuesta en la cual se relacionan diferentes 
conceptos que permitieron clasificar el nivel de conocimiento que poseen los expendedores acerca de la manipulación de alimentos, así como conocer la procedencia y modo de comercialización del producto.

El estudio se realizó en los cinco expendios de pescado fresco y los 10 manipuladores del producto que corresponde al $100 \%$ de la población. Los protocolos establecidos para la toma de muestra, fueron divididos en dos procedimientos importantes para el análisis bacteriológico del pescado: primero en el análisis de las manos, utensilios y superficies. La técnica utilizada fue toma de muestra por barrido/ frotis de manos con escobillones estériles (4) que fueron colocados posteriormente en tubos con $2 \mathrm{~mL}$ de agua peptonada y llevados a neveras de icopor con geles refrigerantes, para asegurar que la temperatura no superara los $10^{\circ} \mathrm{C}$ durante el trasporte, con el fin de mantener la vida útil de la muestra hasta su llegada al laboratorio.

A partir del agua peptonada que sirvió como medio de transporte para los escobillones, se realizó una dilución $10^{-1} \mathrm{y}$ de esta se tomo $1 \mathrm{~mL}$ para sembrar en Agar sangre, Baird Parker y Escherichia coli RAPID agar colonias especificas de color violeta, Agar nutritivo, Sangre, Eosina azul de metileno (EMB) y Baird Parker para superficies y utensilios, en los que se realizó siembra en rejilla. Por cada tubo muestra se efectuó el mismo procedimiento en los medios de cultivo correspondientes al protocolo.

En la segunda fase del estudio se seleccionaron los 30 pescados para el estudio (15 Bagres y 15 mojarras rojas), 3 de cada especie en cada uno de los establecimientos, de acuerdo con la Norma Técnica Colombiana NTC 1443/ 1998 "Requisitos, microorganismos para el pescado crudo refrigeración o congelación" (5) y la NTC 5443/2006 que regula los productos de la pesca y la acuicultura, las buenas prácticas de proceso y comercialización de las especies acuícolas cachama, tilapia y trucha (6).

Inicialmente se seleccionan 3 rodajas de Bagre y 3 unidades de Mojarra roja, de esta ultima se tomaron porciones de diferentes partes del pescado, hasta completar aproximadamente $200 \mathrm{gr}$, observando las condiciones de esterilidad y bioseguridad pertinentes, se realizo la homogenización en el equipo Stomacher

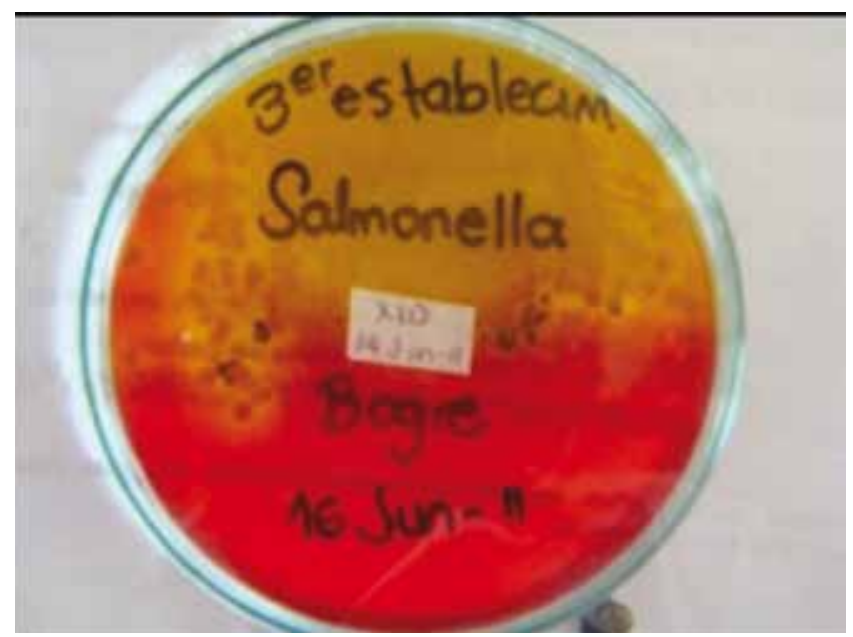

Figura1. Identificación de Salmonella, Agar XLD.

para obtener la muestra adecuada y de la cual se toman 25 gramos para cada análisis (identificación de Salmonella sp, Escherichia Coli, Staphylococcus aureus y Vibrio Cholerae) (3).

\section{Identificación de Salmonella sp.}

Se utilizó el método horizontal descrito en las normas técnicas colombianas NTC 4574/2007 "Microbiología de alimentos y alimentos para animales" y del Manual de análisis bacteriológico (7 -8).

Se realizó un enriquecimiento no selectivo en caldo lactosado, después de 24-48 horas se efectuó el enriquecimiento selectivo inoculando en caldo tetrationato y caldo selenito, para posteriormente hacer una siembra en medios selectivos (XLD y Sulfito bismuto).

Finalmente se realizó la identificación bioquímica mediante la batería de medios para identificar el microorganismo aislado, Figura 1.

\section{Identificación de Vibrio cholerae.}

Se realizó por el método descrito en el Capítulo 9 "para el aislamiento de Vibrio cholerae en alimentos." del Manual de análisis bacteriológico (BAM) (9) además de las pautas señaladas por la Food and Drug Administration.

El pre-enriquecimiento se llevó a cabo en agua peptonada con 3\% de $\mathrm{NaCl}$, luego de 6-8 horas se realizó la siembra en agar selectivo TCBS, las colonias presuntivas fueron sometidas a pruebas bioquímicas, teniendo en cuenta que para este género 


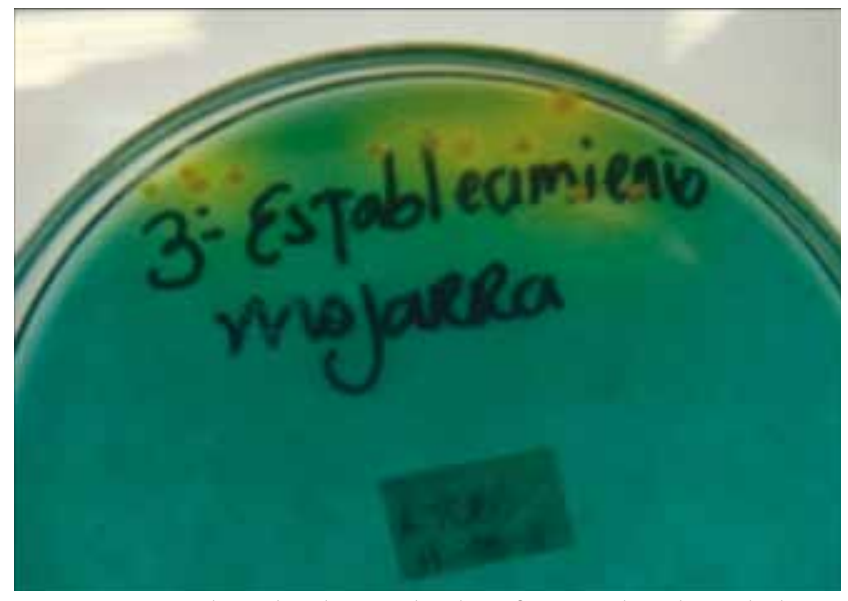

Figura 2. Método utilizado para la identificación de Vibrio cholerae. Agar TCBS.

es indispensable el uso de aminoácidos con una concentración de $0.1 \%$ de $\mathrm{NaCl}$, Figura 2.

\section{Recuento de Escherichia coli}

Para la identificación de Escherichia coli se tuvo en cuenta la metodología expuesta en el inserto de las Placas Petrifilm ${ }^{\mathrm{TM}} 3 \mathrm{M}^{\mathrm{TM}}$ para recuento de Escherichia coli/coliformes, ya que además de ser un método reconocido por la Association of Official Analytical Chemists (AOAC), proporciona una rápida identificación del microorganismo. Se tomó $25 \mathrm{gr}$ del homogenizado y se agregó a $225 \mathrm{~mL}$ de agua peptonada para realizar una dilución $10^{-1}(\mathbf{1 : 1 0})$, luego de esta dilución se tomó $1 \mathrm{~mL}$ y se agregó a $9 \mathrm{~mL}$ de agua peptonada para realizar la dilución $10^{-2}(1: 100)$ y finalmente de esta se tomó $1 \mathrm{~mL}$ para la dilución $10^{-3}(1: 100)$.

Se sembró por duplicado $0.1 \mathrm{~mL}$ de cada una de las diluciones sobre la superficie de la placa de Petrifilm realizando presión con el dispersor para fijar la muestra y se incubo a $35 \pm 2^{\circ} \mathrm{C}$ durante 48 horas, Figura 3.

\section{Recuento de Staphylococcus coagulasa positiva}

Para este procedimiento se utilizó el método descrito en el Capítulo 12 "para el aislamiento de Staphylococcus aureus en alimentos." del Manual de análisis bacteriológico (BAM) (10), además de lo descrito en la metodología analítica para alimentos y bebidas (11) y la NTC 4779/2007 (12).

Se realizaron diluciones seriadas de la muestra que posteriormente fueron sembradas por duplicado

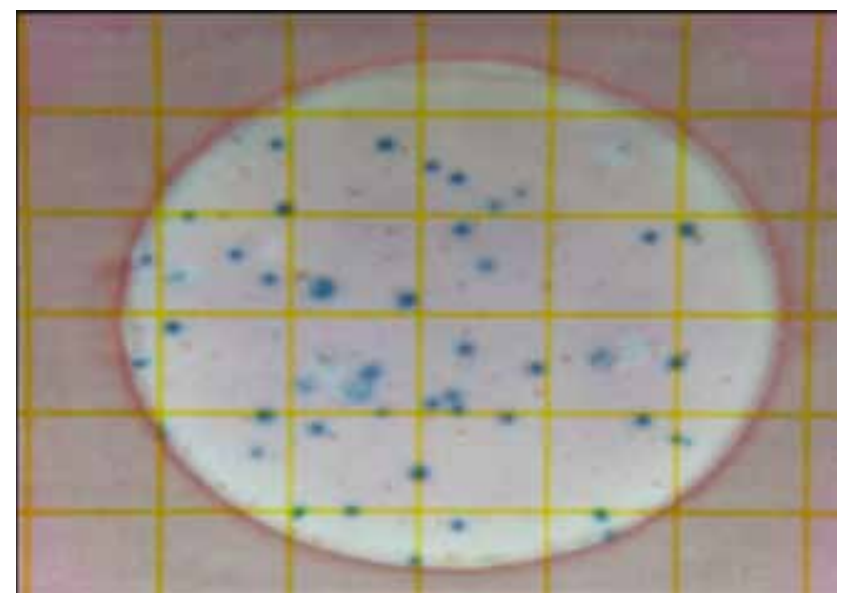

Figura 3. Método utilizado para la identificación de Escherichia coli

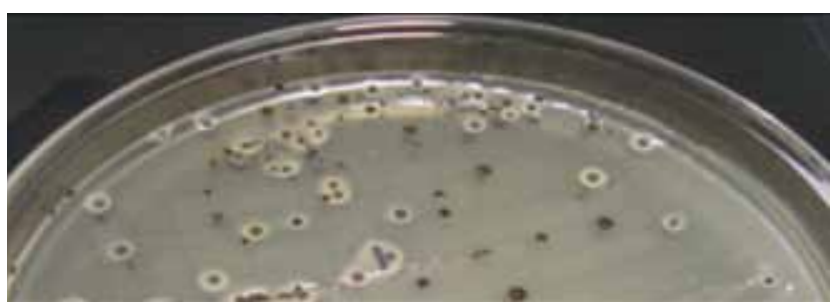

Figura 4. Identificación de Staphylococcus coagulasa positiva. Medio Baird Parker.

$0.1 \mathrm{~mL}$ de las diluciones $10^{-1}$ y $10^{-2}$ sobre la superficie en placas de Petrifilm y la dilución $10^{-3}$ en Agar BairdParker. Pasadas 48 horas se llevó a cabo la prueba de coagulasa correspondiente a las colonias que presentan características típicas, Figura 4.

\section{Resultados}

En el estudio se obtuvieron dos tipos de datos, el primero relacionado con el análisis de la información extraída de las encuestas realizadas a los expendedores y el segundo corresponde al estudio microbiológico, a partir de las muestras de manos, utensilios y superficies, así como de las dos especies de pescado (Bagre y Mojarra Roja), por medio de un método probabilístico no aleatorio.

\section{Resultados de las encuestas}

De acuerdo con la verificación de las condiciones de cada establecimiento: pisos, paredes, techos y demás superficies; se observó que el 60\% se encuentran limpios, y están construidos en material lavable; aunque poseen zonas donde utilizan soportes en madera difíciles de limpiar y desinfectar no 
adecuados para áreas donde se manipulan alimentos, según lo estipulado en el decreto 3075/1997 (13).

Por otra parte, en el $40 \%$ de los establecimientos se observó que los equipos, mesones y utensilios empleados en la manipulación del pescado presentan algún tipo de deterioro como: corrosión, grietas, intersticios u otras irregularidades que pueden atrapar partículas o microorganismos que afectan la calidad sanitaria del producto.

En cuanto a las condiciones del personal y el número de personas que manipulan el alimento se observó que en el $80 \%$ de los establecimientos está a cargo de más de 2 manipuladores, de los cuales el $70 \%$ solo utiliza bata como indumentaria sanitaria, haciendo énfasis en que ninguno hacia uso de gorro y tapabocas. Además se encontró que el $70 \%$ de los expendedores solo utilizan bata sin ningún otro elemento de protección, y un 60\% de ellos no utilizan peto como se muestra en la Figura 5.

De la misma forma, se logro determinar que el $100 \%$ de los manipuladores aseguran realizar el lavado de manos antes de iniciar sus labores. El 20\% efectúa un lavado convencional con solo agua, el 50\% con agua y jabón de barra y el 30\% con agua y jabón antibacterial. Con respecto al secado de manos el 50\% se seca con toalla de tela. Según el Codex alimentariux en un documento básicos en el año 2006 sobre "la seguridad alimentaria: una responsabilidad compartida" menciona el jabón de barra y la toalla de tela como vehículos de contaminación cruzada (14).

Frente a las condiciones del pescado es posible asegurar que el 69\% proviene del Rio Magdalena y de los Llanos orientales, frente a un $23 \%$ proveniente de otras zonas del país.

Con respecto a la temperatura de conservación, el $70 \%$ lo conserva en refrigeración es decir a más

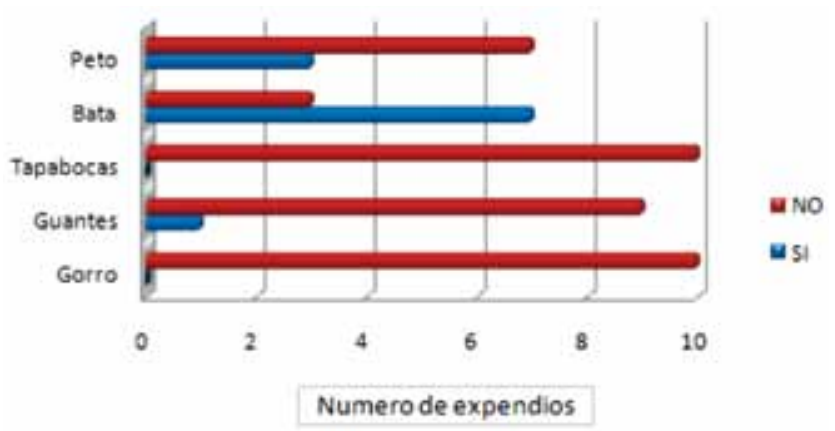

Figura 5. Elementos de protección personal.

o menos $4^{\circ} \mathrm{C}$; en relación al almacenamiento se encontró que el $60 \%$ lo conservan por un periodo aproximadamente de dos a tres días antes de su venta.

\section{Resultados de la fase experimental}

Los recuentos totales en manos arrojaron entre. $7.8 \times 10^{2}$ y $3.15 \times 10^{10}$ UFC y en relación con la presencia de patógenos se evidenció Escherichia coli en el $50 \%$ de los manipuladores y Staphylococcus aureus en el 30\%.

El recuento total en utensilios se determinaron valores que oscilan entre $4.5 \times 10^{3}$ UFC y $1,95 \times 10^{7}$ UFC; en cuanto a los patógenos el $60 \%$ de los establecimientos presentaron valores $>10$ UFC/ superficie muestreada para Escherichia coli y presencia de Staphylococcus aureus en el 100\% las superficies muestreadas para este microorganismo.

Para superficies, los valores oscilaron en entre 8 UFC y $4.6 \times 10^{6}$ UFC y en cuanto a los patógenos el $80 \%$ de los establecimientos presentaron valores $>10$ $\mathrm{UFC} / \mathrm{cm}^{2}$ de la superficiemuestreada para Escherichia coli y el 60\% indicó presencia $/ \mathrm{cm}^{2}$ para Staphylococcus aureus, frente a un $40 \%$ que evidenciaron ausencia total de este patógeno.

En el recuento de Staphylococcus aureus coagulasa

Tabla 1. Recuento de Staphylococcus aureus coagulasa positiva en el pescado mojarra.

\begin{tabular}{lll} 
No Establecimiento & $\begin{array}{c}\text { Recuento Staphylococcus } \\
\text { aureus }\left(\mathbf{N}=\mathbf{\Sigma} \mathbf{c}^{*} \mathbf{d}^{*} \mathbf{1 0}\right)\end{array}$ & \multicolumn{1}{c}{$\begin{array}{c}\text { Otros } \\
\text { microrganismos aislados }\end{array}$} \\
\hline 1 & $<100 \mathrm{UFC} / 25$ gramos & Staphylococcus coagulasa negativa \\
2 & $<100 \mathrm{UFC} / 25$ gramos & Staphylococcus coagulasa negativa \\
3 & $9,0 \times 10^{5} \mathrm{UFC} / 25$ gramos & Staphylococcus coagulasa positiva \\
4 & $<100 \mathrm{UFC} / 25$ gramos & Staphylococcus coagulasa negativa \\
5 & $<100 \mathrm{UFC} / 25$ gramos & Staphylococcus coagulasa negativa \\
\hline
\end{tabular}


Tabla 2. Recuento de Staphylococcus aureus coagulasa positiva en el pescado Bagre.

\begin{tabular}{lll}
\hline $\begin{array}{c}\text { Número de } \\
\text { Establecimiento. }\end{array}$ & $\begin{array}{c}\text { Recuento Staphylococcus } \\
\text { aureus }\left(\mathbf{N}=\mathbf{\Sigma} \mathbf{c}^{*} \mathbf{d}^{*} \mathbf{1 0}\right)\end{array}$ & Otros microrganismos aislados \\
\hline 1 & $<100 \mathrm{UFC} / 25$ gramos & Staphylococcus cohnii \\
\hline 2 & $<100 \mathrm{UFC} / 25$ gramos & Staphylococcus epidermidis \\
\hline 3 & $<100 \mathrm{UFC} / 25$ gramos & Streptococcus constellatus \\
4 & $4,9 \times 10^{5} \mathrm{UFC} / 25$ gramos & Streptococcus constellatus \\
5 & $<100 \mathrm{UFC} / 25$ gramos & Staphylococcus aureus \\
\hline
\end{tabular}

positiva en la Mojarra Roja, Tabla 1 se encontró que el $80 \%$ de la muestra presento Staphylococcus coagulasa negativa con un recuento $<100 \mathrm{UFC} / 25$ gr, y tan solo en el $20 \%$ presentó Staphylococcus coagulasa positiva, correspondiente a un recuento de $9,0 \times 10^{5} \mathrm{UFC} / 25$ gramos.

La Tabla 2 presenta el recuento de Staphylococcus aureus en el Bagre donde se observa que solo el 20\% de las muestras correspondieron a Staphylococcus coagulasa positiva y en el $80 \%$ de los establecimientos la prueba de coagulasa fue negativa.

Para caracterizar las especies de Staphylococcus sp. y Streptococcus sp. aisladas se utilizó la Técnica BBL Crystal $^{\circledR}$, con el software "libro electrónico de códigos BBL Crystal ${ }^{\oplus}$. En el establecimiento 1 se identificó Staphylococcus cohnii con un porcentaje de confianza del 95,3\%, en el establecimiento 2 se descartó la presencia de Staphylococcus aureus, pero se identificó Staphylococcus epidermidis y Streptococcus constellatus con un nivel de confianza del $90 \%$ y $89 \%$ respectivamente; en el establecimiento 3 se identificó Streptococcus constellatus con un porcentaje del $89 \%$ de confianza.

El recuento estimado de Escherichia coli en el pescado Bagre osciló entre 0 y 9,7X10² UFC/25gr, en comparación con el recuento de Coliformes totales que se encontró entre 40 y $1,5 \times 10^{4}$ UFC/25gr.

El recuento realizado en la especie de pescado Mojarra Roja, mostró valores que oscilaron para Escherichia coli entre 0 y 3,7X10² UFC; y Coliformes totales 0 y $1,4 \times 10^{4} \mathrm{UFC}$.

$\mathrm{Al}$ realizar el aislamiento del género Salmonella $s p$. en los dos tipos de pescado se demostró ausencia de Salmonella sp. en el 100\% de las muestras. Sin embargo, se identificaron otro tipo de enterobacterias como se muestra en la Tabla 3. Las enterobacterias aisladas en el Bagre en el 60\% de los establecimientos coincidieron con el género Citrobacter sp., con especies como $C$. amalonaticus y $C$. freundii. Otras enterobacterias aisladas fueron Edwarsiella tarda y Enterobacter cloacae. De las enterobacterias halladas en la Mojarra roja se observa que en el $40 \%$ de los establecimientos, se identificó Klebsiella oxytoca; y en el 60\% restante Enterobacter cloacae, otras enterobacterias identificadas fueron Edwarsiella tarda y Proteus mirabilis.

Es importante mencionar que Klebsiella oxytoca se

Tabla 3. Ausencia o presencia de Salmonella sp. $/ 25$ gr en muestras de pescado Bagre y Mojarra Roja.

\begin{tabular}{lll}
\multicolumn{1}{c}{$\begin{array}{c}\text { Ausencia/presencia } \\
\text { Salmonella sp. / 25 gr } \\
\text { en Bagre y mojarra }\end{array}$} & \multicolumn{1}{c|}{$\begin{array}{c}\text { Otros } \\
\text { microorganismos aislados en } \\
\text { Bagre }\end{array}$} & \multicolumn{1}{c}{$\begin{array}{c}\text { Otros } \\
\text { microorganismos aislados en } \\
\text { mojarra }\end{array}$} \\
\hline 1. Ausencia & Citrobacter amalonaticus & Klebsiella oxytoca \\
2. Ausencia & Citrobacter freundii & Enterobacter cloacae \\
3. Ausencia & Citrobacter freundii & Edwarsiella tarda \\
4. Ausencia & Edwarsiella tarda & Proteus mirabilis \\
5. Ausencia & Enterobacter cloacae & Klebsiella Oxytoca \\
\hline
\end{tabular}


Tabla 4. Ausencia o presencia de Vibrio cholerae /25 gr en muestras de pescado Bagre y Mojarra Roja.

\begin{tabular}{rll}
$r \begin{array}{r}\text { Ausencia/presencia } \\
\text { vibrio cholerae / 25 gr en } \\
\text { Bagre y Mojarra }\end{array}$ & \multicolumn{1}{c}{ Microorganismos aislados en } \\
Bagre & & $\begin{array}{r}\text { Microorganismos aislados en } \\
\text { Mojarra }\end{array}$ \\
Ausencia & Klebsiella oxytoca & Ninguno \\
Ausencia. & Vibrio sp & Ninguno \\
Ausencia & Ninguno & Vibrio metschnikovii \\
Ausencia & Ninguno & Ninguno \\
Ausencia & Ninguno & Klebsiella ozaenae \\
\hline
\end{tabular}

identificó utilizando la técnica BBL Crystal $^{\circledR}$, con el software "libro electrónico de códigos BBL Crystal ${ }^{\circledR}$ con un índice de confiabilidad del $88 \%$.

Por otro lado al aislar Vibrio cholerae se observó ausencia en el 100\% de las muestras de Bagre Tabla 4, por medio de la técnica de Crystal BBL, con 89\% de índice de confiabilidad se identificó Klebsiella oxytoca y a través de pruebas bioquímicas tradicionales se identificó Vibrio sp.

El total de las muestras de Mojarra roja presentó ausencia de Vibrio cholerae, aunque se demostró la presencia de Vibrio metschnikovii en uno de los establecimientos, confirmado a través de la prueba de oxidasa, ya que es el único microorganismo de este género que presenta oxidasa negativa y Klebsiella ozaenae en otro.

\section{Discusión}

En el pescado Bagre se compararon los valores obtenidos con lo que establece la Resolución 776 de 2008 para productos de la pesca (3), en la cual se explicita que el valor máximo permisible para un producto de buena calidad es de $10 \mathrm{UFC} / 25 \mathrm{gr}$ y para un producto de calidad aceptable es de 400 UFC/25gr. De acuerdo con estos parámetros el establecimiento 4 , es decir el $20 \%$ ofrece un producto de buena calidad, el $60 \%$ ofrecen un producto de aceptable calidad para el consumo y otro $20 \%$ se encuentra fuera del rango aceptado por la norma colombiana.

Los recuentos hallados para el pescado Mojarra Roja y los exigidos por la Resolución 776, muestran que el $60 \%$ de los establecimientos ofrecen un producto de buena calidad para el consumidor, frente a un $40 \%$ de los establecimientos correspondiente a los establecimientos 3 y 5 ofrecen un producto de calidad aceptable.

Según los resultados obtenidos en el recuento de Escherichia coli y Staphylococcus coagulasa positiva tanto en las manos, como en superficies y utensilios, son los manipuladores los principales causantes del aumento en estos recuentos por la inadecuada higiene y educación sanitaria, como se evidenció en los resultados de la encuesta y lista de chequeo donde manifestaron que no realizaban un lavado y secado de manos correcto.

De acuerdo con los datos arrojados por el estudio se puede concluir que los recuentos para Bagre aunque se encuentran dentro de la norma son bastante elevados en comparación con los que arrojó el análisis de la Mojarra Roja, esto posiblemente porque el pescado Bagre tiene un proceso de cortado antes de su venta y tiene mayor contacto con el manipulador, con superficies y utensilios contaminados exponiendo el alimento a un mayor riesgo de proliferación no solo de Escherichia coli si no también de Staphylococcus sp. y otros microorganismos.

Entre los microorganismos aislados se encontró Staphylococcus cohnii y Staphylococcus epidermidis, especies coagulasa negativa que hacen parte de la microbiota residente de humanos y animales: en zonas como la piel y las mucosas. Estás especies se asocian con bacteriemias, infecciones nosocomiales, lo que hace que la contaminación exógena con estos agentes microbianos afecte a personas inmunocomprometidas o debilitadas (15).

Un hallazgo importante fue la presencia de Streptococcus constellatus que se aisló e identificó en el Bagre del establecimiento 2. Este microorganismo se encuentra en las mucosas y tracto respiratorio de los humanos, además se constituye como un 
agente patógeno relacionado con el desarrollo de bacteriemia y formación de abscesos, especialmente en pacientes inmunodeprimidos, hasta ahora dicho microrganismo se había identificado en algunas especies de tilapias en países de América Central y del sur, pero no en Bagre (16).

Proteus mirabilis, identificado en las muestras de Mojarra Roja se asocia a procesos de decadencia, porque no solo se encuentra en heces y aguas residuales sino en heridas y carne en descomposición. Además su proliferación tiene una fuerte asociación con las moscas encontradas en los expendios las cuales han sido descritas como una de las fuentes de contaminación con enterobacterias en los alimentos, como se presenta en el estudio realizado en Rio de Janeiro en el 2006, donde no solo reportan estos hallazgos, sino que aclaran que existe mayor predominio de este género en el intestino de las moscas (17).

Durante el aislamiento de Salmonella $s p$. en las especies de Bagre y Mojarra Roja a pesar de la ausencia de este microorganismo en la mayoría de las muestras se encontró otro tipo de Enterobacterias, como Klebsiella oxytoca tanto en el establecimiento 1 como en el 5 en Mojarra Roja, este es un microorganismo Gram negativo que junto a los géneros como Escherichia sp., Citrobacter sp., Enterobacter sp., y Edwarsiella sp. conforman el grupo de Coliformes, sin embargo Klebsiella oxytoca según la Microbiología médica de Jawetz hace parte de la flora intestinal humana y animal y ocasionalmente puede ser aislada de suelos y agua (18) y como se reportó en los resultados obtenidos en la investigación realizada por docentes de la UCMC en la "evaluación de la calidad microbiológica del agua de los Humedales de los Ríos San Jorge y Sinú en el Departamento de Córdoba, Colombia" (19).

En las muestras de Mojarra Roja del establecimiento número dos, se observó la ausencia de Salmonella sp. como se presenta en la Tabla 3, aunque se identificó Enterobacter cloacae el cual se encuentra asociado en varios estudios realizados al medio acuático, donde es capaz de sobrevivir a diferentes condiciones. Además es considerado de importancia en este estudio por ser contaminante fecal capaz de producir graves daños no solo en el pescado sino en el consumidor (20).
Teniendo en cuenta lo anterior la presencia de estos microorganismos en las muestras se asocia principalmente con el agua del lugar de procedencia del pescado que en la mayoría de los casos proviene de los Llanos Orientales y el Rio Magdalena, uno de los ríos más contaminados de Colombia; además de esto también se puede originar por la actividad humana y contaminación fecal aledaña a las fuentes hídricas, (21).

Las especies de la familia Enterobacteriaceae aisladas e identificadas están asociadas a diversos procesos infecciosos, por lo que su presencia debe relacionarse con posibles riesgos en la salud pública, que posiblemente no han sido identificados, por no hacer parte de los cuatro patógenos estipulados. Por ello es necesario continuar con diversas investigaciones para poder agregar nuevos parámetros microbiológicos de aceptación en la normatividad colombiana.

\section{Conclusiones}

Se determinó que las muestras evaluadas se encuentran dentro de los rangos permitidos para el consumo humano de acuerdo con la resolución 776 del 2008, aunque es importante aclarar que la presencia de bacterias diferentes a los patógenos establecidos, puede representar un riesgo para la salud pública.

El pescado se encuentra expuesto a condiciones inadecuadas de higiene por parte de los manipuladores, además de un incorrecto almacenamiento y deficiencia en el uso de las buenas prácticas de manufactura BPM por parte de los expendedores.

Aunque no se encontraron los patógenos contemplados por la normatividad, se logró identificar otro tipo de bacterias pertenecientes a los géneros Citrobacter sp., Enterobacter sp., Klebsiella sp. Edwarsiellasp., Proteussp., Vibrio sp. Staphylococcussp. y Streptococcussp.; donde la especie que presento mayor grado de contaminación fue el Bagre.

Para disminuir el índice de contaminación en el pescado fresco comercializado en los establecimientos en estudio se proponen estrategias para que contribuyan al mejoramiento en las prácticas de manipulación del alimento; dentro de ellas es necesario: 
1. Implementar de forma permanente programas acerca de las BPMs y los correctivos durante el proceso de manipulación y comercialización para el mejoramiento de la calidad del pescado fresco.

2. Establecer y hacer cumplir el protocolo para el lavado de manos, al inicio, durante el proceso y al finalizar las labores de manipulación, para así disminuir la probabilidad de contaminación cruzada. Esto promoviendo entre los expendedores guías estándar que incluyan todos los pasos relacionados desde la higiene personal, hasta la limpieza y sanitización de equipos, utensilios y superficies del establecimiento.

3. Instaurar un control periódico de plagas a través de inspecciones sanitarias que permitan reducir la proliferación de microorganismos contaminantes.

\section{Referencias}

1. Avdalov, N. Manual de calidad y procesamiento para venta minorista de pescado. Proyecto: "Mejoramiento de los mercados internos de productos pesqueros en América Latina y el Caribe"

2. Herrera, F., Santos, A. Prevalencia de Salmonella spp. en pescado fresco expendido en Pamplona (Norte de Santander). Red de revistas científicas Redalyc. 2005;3(2):34-42.

3. Ministerio Protección Social. Resolución 776 de 2006. Establecimiento del reglamento técnico sobre los requisitos fisicoquímicos y microbiológicos que deben cumplir los productos de la pesca, en particular pescados, moluscos y crustáceos para consumo humano, Colombia. 2006.

4. Manual para la toma de muestras para análisis microbiológico. Secretaria Distrital de Salud de Bogotá D.C, Dirección de Salud Pública, 2008.

5. Norma Técnica Colombiana (NTC) 1443/1998 Requisitos microbiológicos para el pescado crudo refrigerado y congelado.

6. Norma Técnica Colombiana (NTC) 5543 del 2006. Productos de la pesca y la acuicultura, las buenas prácticas de proceso y comercialización de las especies acuícolas cachama, tilapia y trucha.
7. Norma Técnica Colombiana (NTC) 4574/2007 Microbiología de alimentos y alimentos para animales. Método horizontal para la detección de Salmonella sp.

8. Food and Drug Administration. Manual de análisis bacteriológicos (BAM). Capitulo 5: Salmonella. Diciembre 2007.

9. Food and Drug Administration. Manual de análisis bacteriológicos (BAM). Capitulo 9: Vibrio. Mayo 2004.

10. Food and Drug Administration. Manual de análisis bacteriológicos (BAM). Capitulo 12: Staphylococcus aureus. Enero 2001

11. Pascual María. Microbiología alimentaria. Metodología analítica para alimentos y bebidas. Ed. Díaz de Santos, S.A. Madrid, España. 1992.

12. Norma Técnica Colombiana (NTC) 4779/2007 Microbiología de alimentos y alimentos para animales. Método horizontal para el recuento de Staphylococcus coagulasa positiva (Staphylococcus aureus y otras especies).

13. Ministerio de Salud. Decreto 3075 de 1997. Colombia. 1997.

14. Codex Alimentariux "la seguridad alimentaria: una responsabilidad compartida". 2006.

15. Louvois J, Gortvai P, Hurley R. Bacteriology of abscesses of the central nervous system: a multicentre prospective study. $\mathrm{Br}$ Med J 1977; 2: 981-984.

16. Brooks G.F, Butel, Microbiología médica de Jawetz. Manual Moderno, México. 2005.

17. Herrera F., J. Santos., A. Otero., M. García-López. Occurrence of foodborne pathogenic bacteria in retail prepackage portions of marine fish in Spain. Journal for Applied microbiology. Vol $\mathrm{N}^{\circ} 100$. Pag. 527-536. Año 2006.

18. Avila S, Estupiñan M. Evaluación de la calidad microbiológica del agua de los Humedales Arcial, El Porro y Cintura (Rio San Jorge), y los Humedales Pantano Bonito y Charco Pescao (Rio Sinú) en el Departamento de Córdoba, Colombia. Universidad Colegio Mayor de Cundinamarca UCMC. 2006.

19. Manual de pruebas de diagnostico para los animales acuáticos 2006. Septicemia entérica del Bagre. Capitulo 2.1.12

20. Oliveira V. Almeida J. Enterobactérias associadas a adultos de Musca domestica (Linnaeus, 1758) (Diptera:Muscidae) e Chrysomya megacephala (Fabricius, 1754) (Diptera: Calliphoridae) no Jardim Zoológico, Rio de Janeiro. Instituto Oswaldo Cruz. Rio de Janeiro, Brasil. 2006:556-561.

21. European committee for standarization. Clean room technology CEN/ TC 243/W G2. 1993. Instituto de salud Publica, Sección Microbiología de Alimentos. Procedimiento recuento de microorganismos en suspensión por método de torunda en superficie. Chile. 2008.
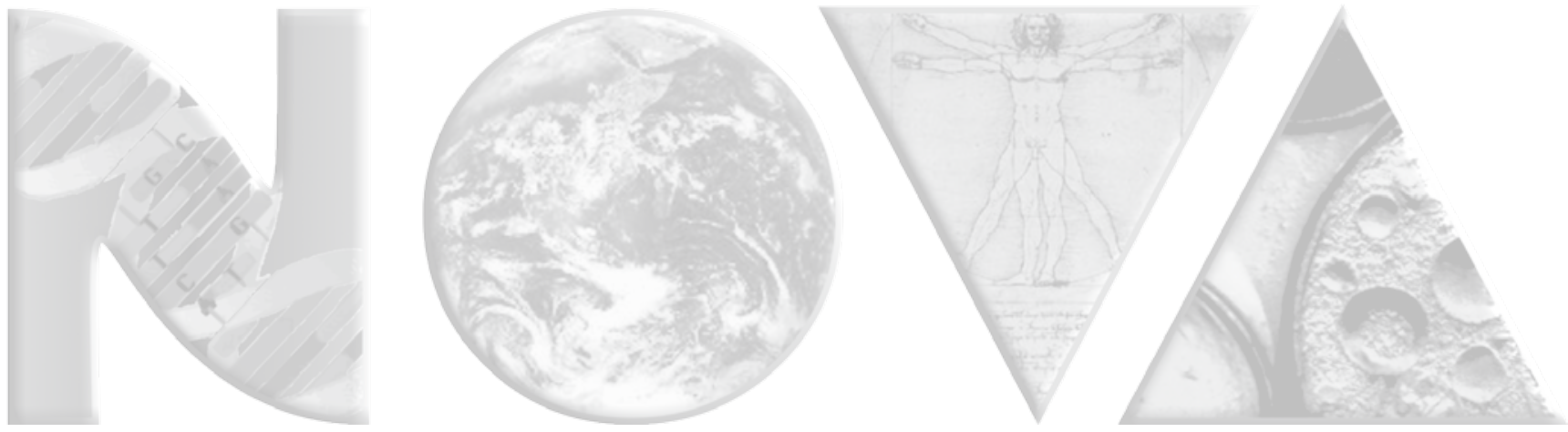